\section{Heritability and Correlations Among Popping Characteristics and Seed Weight in a Broad-based Temperate-adapted Nuña Bean (Phaseolus vulgaris L.) Population}

\author{
Jesse Vorwald ${ }^{1}$ and James Nienhuis ${ }^{2,3}$ \\ University of Wisconsin-Madison, Department of Horticulture, 1575 Linden \\ Drive, Madison, WI 53706-1590
}

Additional index words. popping bean, Andean bean, genetic variance, heritability

\begin{abstract}
Nuña beans are a type of common bean (Phaseolus vulgaris L.) from the Andean region of South America that possess the unique property of popping. To develop temperate-adapted nuña bean cultivars, knowledge is needed regarding the inheritance and relationships among popping characteristics and seed weight. Nuña bean landraces are often photoperiod-sensitive; thus, to obtain estimates of the genetic parameters associated with seed characteristics, populations adapted to the long days of northern temperate climates were developed. Four sets of $\mathbf{1 0}$ families, sampled from a temperate-adapted population, were crossed in a Design II mating design. The heritabilities of seed weight, popping percentage, and the coefficient of expansion were relatively high, $0.77 \pm \mathbf{0 . 0 4}, \mathbf{0 . 8 7} \pm \mathbf{0 . 0 7}$, and $0.74 \pm 0.09$, respectively. Large positive phenotypic $(0.773)$ and additive genetic $(0.539)$ correlations were observed between popping percentage and the coefficient of expansion. Correlations with seed weight were not significant. The results indicate that direct selection for either increased popping percentage or coefficient of expansion will simultaneously improve both traits with little or no change in seed weight.
\end{abstract}

Nuña beans (Phaseolus vulgaris L.) are a type of common bean that possess the unusual property of popping when exposed to heat (National Research Council, 1989). Popping of nuñas results from the expansion of the cotyledons and produces a nut-like product with a flavor similar to that of roasted peanuts. Nuña beans are widely grown in the Andean region of South America but are generally unknown outside their center of origin (National Research Council, 1989). The lack of day-length-insensitive germplasm is likely one of the biological factors that has restricted production and commercialization of nuña beans in temperate regions (Kmiecik and Nienhuis, 1998; National Research Council, 1989; Ogg et al., 1998).

Received for publication 27 May 2008. Accepted for publication 24 Sept. 2008.

This manuscript is a portion of the thesis submitted by Jesse Vorwald in fulfillment of the requirements for a M.S. degree in Horticulture.

This research was supported by the Wisconsin Department of Agriculture, Trade and Consumer Protection Agricultural Development and Diversification Grant Program (WDATCP Contract No. 17076).

We thank Michell Sass and Felix Navarro for their preliminary work on this project and technical assistance.

${ }^{1}$ Graduate Research Assistant.

${ }^{2}$ Professor.

${ }^{3}$ To whom reprint requests should be addressed; e-mail nienhuis@wisc.edu.
1998). To maximize popping percentage and increase the uniformity necessary for a successful product, knowledge is needed regarding the heritabilities and genetic relationships among seed and popping characteristics in a temperate-adapted nuña bean population derived from Andean landraces. The objective of this research was to develop a broadbased temperate-adapted nuña bean breeding population and to estimate the heritability and relationships among seed weight, popping percentage, and the coefficient of expansion.

\section{Material and Methods}

Population development. Six nuña bean landraces with an indeterminate growth habit and photoperiod sensitivity were obtained from the Centro Internacional de Agricultura Tropical, Cali, Colombia (Table 1).

Each of the six landrace accessions were grown at the University of Wisconsin, Walnut Street Greenhouses, Madison, WI, during the short-day winter months and used as females in crosses to 'PB22' and 'PB24', two temperate-adapted nuña bean breeding lines previously developed in our laboratory. 'PB22' and 'PB24' were developed using 'Ayacucho', a nuña landrace from Peru, as a donor parent in a cross and subsequent backcross to the recurrent parent 'Stockbridge Indian Bean' followed by pedigree selection among and within inbred-backcross families (Kmiecik and Nienhuis, 1997). Nuña bean lines 'PB22' and 'PB24' possess the characteristics of photoperiod insensitivity and a determinant growth habit (Type I) necessary for adaptation and production in Wisconsin; they differ primarily in seedcoat color: 'PB24' is uniform brown and 'PB22' is brown-blue (Kmiecik and Nienhuis, 1997). The $\mathrm{F}_{2}$ populations resulting from each of the 12 crosses were field grown in the summer of 1996 at Hancock Agricultural Research Station (ARS), Hancock, WI. Individual plants exhibiting a Type I growth habit and that flowered and produced seed under longdays in Wisconsin were selected within each of the 12 populations. Within each of the 12 populations, photoperiod insensitivity appeared to segregate as a single recessive gene in the populations (data not shown). To confirm segregation for popping, a sample of $10 \mathrm{~F}_{3}$ seeds corresponding to each selected $\mathrm{F}_{2}$ plant was heated in hot oil and the number of unpopped, partial, and fully popped seeds were counted (data not shown). From among several hundred $\mathrm{F}_{2}$ plants, 38 were identified that combined determinate growth habit, the ability to flower under longdays in central Wisconsin, and produced seed that popped.

The $38 \mathrm{~F}_{3}$ families, which represent the reference population for the estimation of genetic variances, were randomly assigned with replacement among four sets of 10 lines each (five as males and five as females) and crossed using a Design II mating design (Comstock and Robinson, 1948). Successful hybridization among the 100 crosses was 
Table 1. Common names and accession numbers of nuña landraces obtained from Centro Internacional de Agricultura Tropical (CIAT), Cali, Colombia, used to develop the temperateadapted nuña breeding lines 'PB24' and 'PB22' and the population for genetic analysis.

\begin{tabular}{lc}
\hline Landrace name & $\begin{array}{c}\text { CIAT accession } \\
\text { number }\end{array}$ \\
\hline Mani palida & $\mathrm{G} 12572$ \\
Mani roja & $\mathrm{G} 12582$ \\
Trabona & $\mathrm{G} 12590$ \\
Callishina oscura & $\mathrm{G} 12587$ \\
Azul grande & $\mathrm{G} 12577$ \\
Pava nuña & $\mathrm{G} 19646$ \\
\hline
\end{tabular}

confirmed by planting three to 10 seeds from pods of crosspollinated flowers; the phenotype of assumed hybrid plants was compared with their corresponding male and female parents grown in adjacent rows at the Arlington ARS, Arlington, WI, in the summer of 1999. $F_{2}$ seed was harvested and bulked from three to $10 \mathrm{~F}_{1}$ plants within each row that exhibited phenotypic characteristics of both parents.

The $25 \mathrm{~F}_{3}$ families corresponding to each of the four sets were planted in four random blocks (sets) with two replications and evaluated over 2 years, 2002 and 2003, at the Arlington ARS, Arlington, WI. Twenty seeds were double-seeded $\approx 10 \mathrm{~cm}$ apart in $1-\mathrm{m}$ rows and later thinned after the unifoliate leaves appeared to the 10 most uniformly dispersed plants in each row. Standard cultural practices were used to control weeds (Binning et al., 1995). When pods were completely dry and physiologically mature, the plants within each row were clipped off at the soil surface, placed in gunnysacks, and allowed to air dry in a greenhouse at the Arlington ARS for $\approx 1$ month. Seed was cleaned using a mechanical thrasher followed by hand cleaning and winnowing. The seed was dried in a forced-air oven at $50{ }^{\circ} \mathrm{C}$ to $\approx 5 \%$ moisture (Tector Sinar $^{\mathrm{TM}}$ Farmpro 6090 Moisture Analyzer; Sinar Technology, Berkshire, U.K.).

Testing and data analysis. Fifty seeds were randomly sampled from each plot and seed weights were calculated. Seed of two plots were inadvertently popped before being weighed; thus, seed weight data for these two plots were lost. Each 50-seed sample was placed into a graduated cylinder and distilled water was added until the total volume of water and seeds equaled $25 \mathrm{~mL}$. The total volume of water added was subtracted from the total volume to give the unpopped seed volume (UNPV). The seeds were drained and patted dry with paper toweling and immediately popped to minimize absorption of water into the seed. Seed was popped in a Presto Hot Air Popper model 04821 (National Presto Industries, Inc., Eau Claire, WI) for $90 \mathrm{~s}$ at $244{ }^{\circ} \mathrm{C}$ following recommendations for optimal popping of nuña beans (Vorwald and Nienhuis, 2008). The volume of seed after popping (PV) was obtained using a procedure similar to that used for unpopped seed. A seed was considered fully popped when the cotyledons had expanded sufficiently to shed the seedcoat. A seed was considered unpopped or partially popped if the seedcoat failed to crack or no expansion of the cotyledons was observed. The coefficient of expansion (including fully popped, partial, and unpopped seeds) was calculated as $[(\mathrm{PV}-\mathrm{UNPV}) / \mathrm{UNPV}] \times 100$ in which $\mathrm{UNPV}=$ unpopped volume and $\mathrm{PV}=$ popped volume. The popping percentage was calculated as the percentage of 50 seeds that were fully popped. For purposes of analysis of variance and covariance, the popping percentage data were transformed using arcsine ${ }^{-1}$ to better approach normality; however, means are expressed as untransformed data to facilitate interpretation of the results. For analyses of variance and covariance, the data were analyzed using the standard least squares procedure of JMP statistical software, Version 7 (SAS Institute, Inc., Cary, NC). Genetic components of variance and covariance were obtained by setting observed means squares or crossproducts equal to expected values and solving for the desired component (Hallauer and Miranda, 1981). No significant deviation from homogeneity of variance between male $\left(\sigma_{\mathrm{m}}^{2}\right)$ and female $\left(\sigma_{f}^{2}\right)$ components of variance was observed; thus, the estimate of additive genetic variance $\left(\sigma_{\mathrm{A}}^{2}\right)$ for all traits was obtained by pooling mean squares (Hallauer and Miranda, 1981). Estimates of narrow sense heritability $\left(\mathrm{h}^{2}\right)$ on an entry mean basis and unbiased by genotype $\times$ environment interactions and corresponding SES were calculated (Hallauer and Miranda, 1981)

\section{Results and Discussion}

Year was the source of variance with the largest mean square for seed weight, popping percentage (PopPct), and coefficient of ex- pansion (CoE) (Table 2). The 2003 growing season was characterized by lower and more erratic rainfall compared with that of 2002 , which may have contributed to the $22 \%$, $16 \%$, and $13 \%$ reduction in seed weight, PopPct, and $\mathrm{CoE}$, respectively (Table 2). First- and second-order genotype $\times$ environment interactions, e.g., males/sets $\times$ year, female/sets $\times$ year, and male $\times$ female/sets $\times$ year, were not significant for seed weight, indicating that differences among families were consistent over years. Heritability of seed weight in this nuña bean population, $0.77 \pm 0.04$, is similar in magnitude to previous estimates, $0.74 \pm 0.15$, obtained using a Design II mating design in a dry bean population (Nienhuis and Singh, 1988). Variance among half-sib families (males and females nested in sets) was significant for both PopPct and CoE. First-order and second-order genotype $\times$ environment interactions were significant for PopPct, but only first-order interactions were significant for CoE. The heritability of PopPct and CoE in this temperate-adapted nuña bean population was relatively high, $0.87 \pm 0.07$ and $0.74 \pm$ 0.09 , respectively.

Although care and experience were exercised to visually confirm that seed was harvested from hybrid rather than selfed families in the development of the Design II matings, hybridization was not confirmed with DNA-based molecular markers. Evaluation of unintended selfed families in a Design II mating design would increase variation among half-sib families (males and females nested in sets) and interactions between males and females in sets resulting in an upward bias in the estimation of heritability of traits (Hallauer and Miranda, 1981). The relatively high heritability estimates are consistent with empirical results of field-based selection among inbred-backcross

Table 2. Analysis of variance, heritability, and year means for seed weight, percentage of fully expanded seeds after popping (popping percentage), and coefficient of expansion in a temperate-adapted nuña bean population.

\begin{tabular}{|c|c|c|c|c|}
\hline \multirow[b]{2}{*}{ Source } & \multirow[b]{2}{*}{$\mathrm{df}$} & \multicolumn{3}{|c|}{ Mean squares } \\
\hline & & Seed wt $(g)^{z}$ & Popping percentage ${ }^{y}$ & $\begin{array}{l}\text { Coefficient of } \\
\text { expansion }^{\mathrm{x}}\end{array}$ \\
\hline$\overline{\text { Year }(Y)}$ & 1 & $420.5 * * * *$ & $5,323.3^{* * * *}$ & $3,743.2 * * * *$ \\
\hline Sets $(\mathrm{S})$ & 3 & $12.0 \mathrm{NS}$ & $105.3 \mathrm{NS}$ & $226.2 \mathrm{NS}$ \\
\hline $\mathrm{Y} \times \mathrm{S}$ & 3 & $4.4 \mathrm{NS}$ & $61.9 \mathrm{NS}$ & $243.4 \mathrm{NS}$ \\
\hline $\operatorname{Rep}(Y \mathrm{~S})$ & 8 & $3.5 \mathrm{NS}$ & $121.9 * *$ & $345.0 * *$ \\
\hline Males (S) & 16 & $17.2 *$ & $386.6 * * * *$ & $453.7 * * *$ \\
\hline Females (S) & 16 & $18.0^{*}$ & $192.6^{* * *}$ & $257.6 * *$ \\
\hline $\mathrm{M} \times \mathrm{F}(\mathrm{S})$ & 64 & $13.5^{*}$ & $135.7 * * *$ & $233.7 * *$ \\
\hline$M \times Y(S)$ & 16 & $5.5 \mathrm{NS}$ & $207.5 * * * *$ & $331.4 * *$ \\
\hline $\mathrm{F} \times \mathrm{Y}(\mathrm{S})$ & 16 & $4.7 \mathrm{NS}$ & $128.8 * *$ & $264.7 * *$ \\
\hline $\mathrm{F} \times \mathrm{M} \times \mathrm{Y}(\mathrm{S})$ & 64 & $14.8 \mathrm{NS}$ & $140.6^{* * * *}$ & $189.0 \mathrm{NS}$ \\
\hline \multirow[t]{5}{*}{ Pooled error } & $192(190)^{\mathrm{w}}$ & 12.0 & 67.8 & 176.9 \\
\hline & $\mathrm{h}^{2 \mathrm{v}} \pm \mathrm{SE}$ & $0.77 \pm 0.04$ & $0.87 \pm 0.07$ & $0.74 \pm 0.09$ \\
\hline & & & Year means & \\
\hline & 2002 & 18.0 & 79.2 & 61.3 \\
\hline & 2003 & 14.8 & 68.1 & 54.2 \\
\hline
\end{tabular}

${ }^{\mathrm{z}}$ Seed weights based on mean of 50 seeds.

${ }^{y}$ Popping percentage of fully popped seed ( $\operatorname{arcsine} e^{-1}$ transformed).

${ }^{x}$ Volume of 50 seed samples before and after popping.

${ }^{\text {w}}$ Degrees of freedom for seed weight (two plots that were popped before weighing).

varrow sense heritability on entry mean basis.

$\mathrm{NS}, *, * *, * * *, * * * *$ Nonsignificant and significant at $P \leq 0.05,0.01,0.001$, and 0.0001 levels, respectively. 
families for improved popping percentage (Kmiecik and Nienhuis, 1997; Ogg et al., 1998). Selection for increased coefficient of expansion has been successful in popcorn and may also be a desirable trait in nuña beans because greater seed expansion may result in a softer texture and improved palatability (Hoseney et al., 1983; Lyerly, 1942). Results of this study indicate that direct selection among family means should be effective in increasing seed weight, PopPct, and $\mathrm{CoE}$ in this broad-based, temperate-adapted nuña bean population.

The only significant phenotypic correlation among traits was observed between PopPct and CoE; the magnitude of the corresponding additive genetic correlation was similar in sign and magnitude (Table 3). PopPct and CoE were not significantly correlated with seed weight. These results suggest that PopPct and $\mathrm{CoE}$ can be increased simultaneously by selection for either trait in this temperate-adapted nuña bean population.

Table 3. Phenotypic (above diagonal) and additive genetic (below diagonal) correlations among seed weight, popping percentage, and coefficient of expansion in a temperateadapted nuña bean population.

\begin{tabular}{cccc}
\hline & $\begin{array}{c}\text { Seed } \\
\text { wt }(\mathrm{g})^{\mathrm{z}}\end{array}$ & $\begin{array}{c}\text { Popping } \\
\text { percentage }^{\mathrm{y}}\end{array}$ & $\begin{array}{c}\text { Coefficient of } \\
\text { expansion }^{\mathrm{x}}\end{array}$ \\
\hline $\begin{array}{c}\text { Seed } \\
\text { weight }(\mathrm{g})\end{array}$ & - & $0.132 \mathrm{NS}$ & $0.025 \mathrm{NS}$ \\
$\begin{array}{c}\text { Popping } \\
\text { percentage }\end{array}$ & 0.111 & - & $0.539^{* * *}$ \\
$\begin{array}{c}\text { Coefficient } \\
\text { of expansion }\end{array}$ & 0.345 & 0.773 & - \\
\hline
\end{tabular}

${ }^{\mathrm{z}}$ Seed weights based on mean of 50 seeds.

${ }^{\mathrm{y}}$ Popping percentage of fully popped seed (arcsine $^{-1}$ transformed).

${ }^{x}$ Volume of 50 seed samples before and after popping.

$* * *$, NS $=$ Phenotypic correlation significant at $P \leq$ 0.001 level and nonsignificant, respectively.
In a practical plant breeding program, it may be more efficient to select for PopPct compared with $\mathrm{CoE}$.

\section{Conclusion}

Popping percentage is the most important trait for commercialization of nuña beans because removal of unpopped seed from a product represents an added expense to the processor and a glaring defect to the consumer (Song et al., 1991). Expansion of the popped product may also be beneficial to commercialization of nuña beans by providing a softer, more palatable product. The results from this study indicate that selection among family means in this temperateadapted nuña bean population can be effective in increasing popping percentage, and correlated responses to selection will result in improved expansion of the popped product with little or no change in seed weight. The seedcoat colors of the 100 full-sib families ranged from dull brown to mottled red. After popping, the seedcoat of nuña beans is oxidized by the intense heat in the popping chamber and shed; thus, seedcoat color will likely only be important for eye appeal in commercialization of unpopped nuña bean products.

\section{Literature Cited}

Binning, L.K., C.M. Boerboom, L.G. Bundy, D. Curwen, E.T. Gritton, H.C. Harrison, H.J. Hopen, K.A. Kelling, S.E.R. Mahr, B.A. Michaelis, P.J. Schmidt, W.R. Stevenson, W.F. Tracy, J.L. Wedberg, and J.A. Wyman. 1995. Commercial vegetable production in Wisconsin. UWEX. Bul. A3422. Univ. of Wisconsin Press, Madison, WI.

Comstock, R.E. and H.F. Robinson. 1948. The components of genetic variance in populations of biparental progenies and their use in estimating the average degree of dominance. Biometrics 4:254-266.
Crumbaker, D.E., I.J. Johnson, and J.C. Eldredge. 1949. Inheritance of popping volume and associated characters in crosses between popcorn and dent corn. Agron. J. 41:207-215.

Hallauer, A.R. and J.B. Miranda. 1981. Quantitative genetics in maize breeding. Iowa State Univ. Press, Ames, IA.

Hoseney, R.C., K. Zeleznak, and A. Abdelrahman. 1983. Mechanism of popcorn popping. J. Cereal Sci. 1:43-52.

Kmiecik, K. and J. Nienhuis. 1997. Development of nuña beans with temperate zone adaptation. Annu. Rpt. Bean Improv. Coop. 40:36-37.

Kmiecik, K. and J. Nienhuis. 1998. Recent notes and observations on: Standardization of popping and evaluations of nuña germplasm. Annu. Rpt. Bean Improv. Coop. 41:220.

Lyerly, P.J. 1942. Some genetic and morphological characters affecting the popping expansion of popcorn. J. Amer. Soc. Agron. 41:986-999.

National Research Council. 1989. Lost crops of the Incas. National Academy Press, Washington, DC.

Nienhuis, J. and S.P. Singh. 1988. Genetics of seed yield and its components in common bean (Phaseolus vulgaris L.) of Middle American origin. II. Genetic variance, heritability and expected response from selection. Plant Breed. 101:155-163.

Ogg, B., M.A. Brick, and C. Pearson. 1998 Introgression of popping ability into dry beans adapted to Colorado. Annu. Rpt. Bean Improv. Coop. 41:35-36.

Song, A., S.R. Eckhoff, M. Paulsen, and J.B. Litchfield. 1991. Effects of kernal size and genotype on popcorn popping volume and number of unpopped kernels. Cereal Chem. 68:464-467.

Tohme, J., O. Toro, J. Vargas, and D.G. Debouck. 1995. Variability in Andean nuña common beans (Phaseolus vulgaris L.). Econ. Bot. 49:78-95.

Vorwald, J.A. and J. Nienhuis. 2009. Effects of seed moisture content, cooking time and chamber temperature on nuña bean (Phaseolus vulgaris L.) popping. HortScience. 44:135-137.

Zimmer, K.S. 1992. Biological diversity and local development: 'Popping beans' in the Central Andes. Mt. Res. Dev. 12:47-61. 